UPPSALA UNIVERSITET
Working Paper 2007:7

Department of Economics

Public Provision of Private Goods and Nondistortionary Marginal Tax Rates

Sören Blomquist and Vidar Christiansen 
Department of Economics

Uppsala University

P.O. Box 513

SE-751 20 Uppsala

Sweden

Fax: +46184711478
Working paper 2007:7

January 2007

ISSN 1653-6975

\section{Public Provision of Private Goods and Nondistortionary Marginal TAX RATES}

SöREn BlomQuist and Vidar Christiansen

Papers in the Working Paper Series are published on internet in PDF formats.

Download from http://www.nek.uu.se

or from S-WoPEC http://swopec.hhs.se/unnewp/ 


\title{
Public Provision of Private Goods and Nondistortionary Marginal Tax Rates
}

\author{
by \\ Sören Blomquist \\ Department of Economics, Uppsala University ${ }^{1}$ \\ and \\ Vidar Christiansen \\ Department of Economics, University of Oslo ${ }^{2}$
}

\begin{abstract}
The incidence and efficiency losses of taxes have usually been analysed in isolation from public expenditures. This negligence of the expenditure side may imply a serious misperception of the effects of marginal tax rates. The reason is that part of the marginal tax may in fact be payment for publicly provided commodities and reflect a cost that the consumers should bear in order to face the right incentives. Hence, part of the marginal tax serves the same role as a market price in the sense that it conveys information about a real social marginal cost of working more hours.

We develop this idea formally by studying an optimal income tax model in combination with a type of public provision scheme not analyzed before; the provision level is individualized and positively associated with the individuals' labour supply. As examples we discuss day care, elderly care, primary education and health care. We show that there is a gain in efficiency if public provision of such a service replaces market purchases. We also show that it is necessary for efficiency that marginal income tax rates are higher than in economies where the services are purchased in the market. This is because the optimal tax should be designed so as to face the taxpayers with the real cost of providing the services. Hence, it might very well be that economies with higher marginal tax rates have less severe distortions than economies with lower marginal tax rates. We also explore whether an efficiency gain is achievable by alternatively making day care expenses tax deductible and derive a negative conclusion.
\end{abstract}

Keywords: Marginal income tax; public provision; private goods; in-kind transfer; tax deductions JEL classification: H21, H42, I38

1 Box 513, 75120 Uppsala, Sweden. E-mail: Soren.Blomquist@nek.uu.se

2 Box 1095, Blindern 0317Oslo, Norway. E-mail: Vidar.Christiansen@econ.uio.no 


\section{Introduction}

A common view is that high marginal income tax rates generate large efficiency losses. Although this often might be true, we will in this paper show that this view should be nuanced. The incidence and efficiency losses of taxes have usually been analysed in isolation from public expenditures. We will argue that negligence of the expenditure side may imply a serious misperception of the effects of marginal tax rates. The reason is that part of the marginal tax may in fact be payment for publicly provided commodities and reflect a cost that the consumers should bear in order to face the right incentives. That is, marginal tax rates sometimes play the same role as prices in the sense that they convey information on resource costs.

Public provision of private goods is common in all developed countries and often is in the order of 20-30\% of GDP. Previous work has usually considered public provision schemes that furnish each consumer with the same fixed quantity. ${ }^{3}$ In this paper we address another type of public provision scheme, not analysed before. ${ }^{4}$ Every person gets exactly the amount that he wants. For such a system to be viable the good in question must have the property that there is satiation in consumption, even if satiation levels may vary across consumers. In section 5 where we study some examples we will argue that several important public provision schemes are of a form such that the demand for the service in question depends on the hours of work and that for given hours of work there is a satiation point. In this paper we will study the implications for the optimal marginal income taxes of such provision systems.

As a vehicle for our analysis we will use an extension of the Stern (1982) and Stiglitz (1982) two type version of Mirrlees’ optimal income tax model (Mirrlees (1971)). A non-linear redistributive income tax is imposed under the asymmetric information that knowledge of who is high-skilled and who is low-skilled is private information not available to the government. The tax schedule must then be designed subject to the self-selection constraint ensuring that a highskilled person does not select an income point intended for a low-skilled person (a behaviour referred to as mimicking). If the high-skilled person were to mimic, he would obtain more leisure than the low-skilled person with the same income as, being more productive, the high-skilled person could earn the same income in less time. However, if some of the transfer is given in kind,

\footnotetext{
${ }^{3}$ See, for example, Blomquist and Christiansen (1995), Boadway and Marchand (1995), Cremer and Gahvari (1997), Balestrino (2000) and Pirttilä and Tuomala (2002).

${ }^{4}$ We want to emphasize that what we study in this paper is public provision, i.e. publicly financed goods. Whether the goods are privately or publicly produced does not matter for our analysis.
} 
it may be of less value to the mimicker than to the genuine low-skilled type if the good being transferred is less beneficial to someone who has more leisure time. Shifting to a transfer in kind may therefore make mimicking less appealing, and thus alleviate the self-selection constraint and enhance welfare. Given the particular type of provision system we study here, it will also be the case that the marginal tax should reflect the real marginal social cost of more hours of work. That is, part of the marginal tax serves the same role as a market price in the sense that it conveys information about a real social cost of working longer hours, but the tax is on balance more efficient as it also discourages mimicking, as emphasised above.

In section 2 of the paper we set up the model we will use and show how a strict Pareto improvement can be obtained by supplementing the optimal tax solution with a publicly provided private good. In section 3 we characterize the optimal tax/public provision scheme and show that the real social cost of providing the private good in question should be reflected in individuals' marginal tax rates. In section 4 we investigate if tax deductibility is a good substitute for public provision. Section 5 discusses some examples. Finally, section 6 concludes.

\section{The Model}

If there are only two skill types, a system where all individuals get as much of the publicly provided good as they want and a system designed so that the type with the lowest demand gets the amount he wants and the other type can top up, will be equivalent. We therefore assume there are three skill levels reflected by wage rates $w^{1}, w^{2}$, and $w^{3} ; w^{1}<w^{2}<w^{3}$. We let $h$ denote hours of work and $Y(=w h)$ the before tax labor income. We also make the usual assumption that the policy maker can observe $Y$ but not $w$ or $h$ separately. Each agent chooses how much labour to supply and the corresponding consumption level, which also depends on the tax liability. There is a private good/service which is a candidate for public provision. The demand for this good, which we in the following will call the $x$-good, is strictly related to the hours of work, i.e. $x=f(h)=f(Y / w)$. A simple case we will consider later is the one where $f(h)=h=Y / w$. The $x$-good does not enter the utility function directly. It is instead a good/service one must acquire in order to work. Hence, it entails a cost of working. The best example is probably day care. A fixed number of children must be cared for either by the parents themselves or by day-care centres. We will discuss further examples in section 5. 
The different skill types have identical preferences over leisure and consumption, which is equal to disposable income net of the amount spent on the $x$-good. Since every person has the same time endowment, there is a unique relationship between working time and leisure and it is a matter of convenience whether preferences are expressed as preferences for leisure or for work. We opt for the latter alternative and write the direct utility function as $u(C, h)$, where $\mathrm{C}$ is consumption exclusive of expenditures on the $x$-good.

We let $Y^{i}$ and $B^{i}$ denote respectively the before and after tax income of a person of type $i$, with a higher index indicating a higher ability. The labour supply of type $i$ can then be expressed as $Y^{i} / w^{i}$. We denote the resource cost of the $x$-good by $p$ per unit, which would be the price in a competitive market. In a situation without public provision of $x$ the consumption level of type $i$ is then $C^{i}=B^{i}-p f\left(Y^{i} / w^{i}\right)$, and we can write the utility function as $u\left(B^{i}-p f\left(Y^{i} / w^{i}\right), Y^{i} / w^{i}\right)$. Following the convention of suppressing $w^{i}$ in the latter argument, we write the utility function as $U^{i}\left(B^{i}-p f\left(Y^{i} / w^{i}\right), Y^{i}\right)$. If the $x$-good is publicly provided free of charge, the relevant utility function is $U^{i}\left(B^{i}, Y^{i}\right) \equiv u\left(B^{i}, Y^{i} / w^{i}\right)$.

We note that in the situation without any taxes or public intervention the individual's budget constraint would be $C=w h-p f(h)$ and the marginal net wage rate would be given by $(d C / d h)_{B C}=w-p f^{\prime}(h)$. (In $Y, B$ space it would read $(d C / d Y)_{B C}=1-(p / w) f^{\prime}(Y / w)$.) The

utility function would take the form $U^{i}\left(Y^{i}-p f\left(Y^{i} / w^{i}\right), Y^{i}\right)$ with F.O.C. $(d C / d Y)_{\bar{U}}=1-(p / w) f^{\prime}(Y / w)$, i.e. $M R S_{C Y}=M R T_{C Y}$ and there would be no distortions.

We assume the standard single crossing property that for any fixed gross and net income point in $Y, B$-space the indifference curve of a lower ability type is steeper than that of a higher ability type.

\section{A Pareto Improving Public Provision Scheme}

The way to show how public provision of the $x$-good yields a Pareto improvement is similar to the way this is done in earlier studies. However, to make the paper more self-contained we briefly describe the mechanism. As in the conventional two-type model, we assume that the government imposes a positive net tax on the high-skilled agent and makes a transfer to the low skilled types. The conditions for the optimal income tax are standard and are not derived here. Let us just recall 
that the income tax must be designed subject to the self-selection constraints that a type 3 individual should not mimic type 2 by choosing the income point ( $B, Y$-bundle) intended for the latter type, and likewise type 2 should not mimic type 1 . The implication of these constraints is that the leisure-consumption choices of the two low skill groups must be distorted so that they work too little as compared to first best. Relaxation of any of these self-selection constraints will allow a Pareto improving tax reform where the low skill groups face smaller distortions than before; they will work more, have higher consumption and higher utility.

We will show how a strict Pareto improvement can be obtained by introducing public provision of the $x$-good being financed by (increased) taxes. Since there is satiation (conditional on labor supply) the public sector can offer any amount free of charge. Conditional on his labor supply, each person will then choose the amount that he needs. Without satiation, at a reasonable level, it will not be possible to offer any amount free of charge as each consumer would then expand his consumption beyond any reasonable limit.

The demand for the $x$-good is given by $x^{i}=f\left(Y^{i} / w^{i}\right), i=1,2,3$, for the actual types and for mimicking individuals we would have $f\left(Y^{i} / w^{i+1}\right), i=1,2$. It is evident that $Y^{i} / w^{i+1}<Y^{i} / w^{i}$ as the mimicked person has a lower wage rate than the mimicker. This simply means that the mimicker, being more productive, will earn the same income in less time and hence demand less of the $x$-good. We let the actual individuals get the amount of $x$ they want and decrease the aftertax incomes by $p f\left(Y^{i} / w^{i}\right), i=1,2,3$. Hence, the situation for the actual persons is unchanged. However, a mimicker is forced to pay, via taxes, for more of the $x$-good than they need by an amount , $p\left(f\left(Y^{i} / w^{i}\right)-f\left(Y^{i} / w^{i+1}\right)\right), i=1,2$, and hence suffer a loss of utility, implying that the self-selection constraints will no longer bind. This means that we can change the income point for the low-skill individuals to a point where their consumption-leisure bundle is less distorted, i.e. they will work more and have a higher consumption. Hence, we can improve welfare for the low skill persons without hurting the more able people.

\section{Characterization of the Optimal Tax-Public Provision Optimum}

To characterise the Pareto optimal policy we assume that the policy maker maximizes the utility

of the low-skill group subject to pre-set minimum utility levels ( $\bar{U}^{2}$ and $\bar{U}^{3}$, respectively) for the medium and high-skill group, and subject to the relevant self selection constraints and the 
government budget constraint. Using the notation that a double superscript $i j$ indicates type $i$ when mimicking type $j$ the Lagrange function of this optimisation problem will take the form:

$$
\begin{aligned}
& \Lambda=U^{1}\left(B^{1}, Y^{1}\right)+\lambda_{2}\left(U^{2}\left(B^{2}, Y^{2}\right)-\bar{U}^{2}\right)+\lambda_{3}\left(U^{3}\left(B^{3}, Y^{3}\right)-\bar{U}^{3}\right)+\beta_{2}\left(U^{2}\left(B^{2}, Y^{2}\right)-U^{21}\left(B^{1}, Y^{1}\right)\right) \\
& +\beta_{3}\left(U^{3}\left(B^{3}, Y^{3}\right)-U^{32}\left(B^{2}, Y^{2}\right)\right) \\
& +\mu\left(\left(Y^{1}-B^{1}\right)+\left(Y^{2}-B^{2}\right)+\left(Y^{3}-B^{3}\right)-p f\left(\frac{Y^{1}}{w^{1}}\right)-p f\left(\frac{Y^{2}}{w^{2}}\right)-p f\left(\frac{Y^{3}}{w^{3}}\right)\right)
\end{aligned}
$$

The first and the second constraint (with Lagrange multipliers $\lambda_{2}$ and $\lambda_{3}$ ) are the minimum utility requirements for the medium- and high-skilled individuals. The third restriction (with multiplier $\beta_{2}$ ) is the self-selection constraint that the utility that the medium-skilled person can obtain by mimicking the low-ability person should not exceed the utility level actually intended for him. The next constraint (with multiplier $\beta_{3}$ ) is the similar self-selection constraint on the high-skilled person. The last constraint (with shadow price $\mu$ ) is the government budget constraint with the cost of provision of the $x$-good on the expenditure side.

Standard first order conditions are derived in an appendix. Invoking those results we obtain

$$
M R S^{3}=\frac{-U_{Y}^{3}}{U_{C}^{3}}=1-\frac{p}{w^{3}} f^{\prime}\left(\frac{Y^{3}}{w^{3}}\right)
$$

from (a13). From (a11) and (a12) we obtain

$$
\begin{aligned}
& M R S^{1}=\rho_{2}\left(M R S^{21}-M R S^{1}\right)+1-\frac{p}{w^{1}} f^{\prime}\left(\frac{Y^{1}}{w^{1}}\right)<1-\frac{p}{w^{1}} f^{\prime}\left(\frac{Y^{1}}{w^{1}}\right), \\
& M R S^{2}=\rho_{3}\left(M R S^{32}-M R S^{2}\right)+1-\frac{p}{w^{2}} f^{\prime}\left(\frac{Y^{2}}{w^{2}}\right)<1-\frac{p}{w^{2}} f^{\prime}\left(\frac{Y^{2}}{w^{2}}\right),
\end{aligned}
$$

where $M R S=-U_{Y} / U_{C}, \rho_{2}=\beta_{2} U_{C}^{21} / \mu>0, \rho_{3}=\beta_{3} U_{C}^{32} / \mu>0$, and the inequalities follow because $M R S^{i j}<M R S^{j}$ for $i>j$, which is the standard assumption that a more able type of individual has the flatter indifference curve through any given point in $Y, B$-space.

According to condition (2) the labor supply of the type three person is undistorted. Since resources must be allocated to the $x$-good, every hour of work inflicts a real cost of $p f^{\prime}\left(Y^{3} / w^{3}\right)$ on society, which should be reflected in the worker's budget constraint to provide the right incentives for labor supply and make sure that $M R S=M R T$ in terms of consumption and leisure. This is exactly the content of condition (2). The marginal rate of substitution (MRS) between 
gross and net income on the left hand side expresses the compensation in terms of consumption required to offset the disutility from earning an additional unit of gross income. In other words, this is a money measure of the marginal disutility of acquiring further income. According to (2) this marginal disbenefit should be equated to the extra income actually generated after deducting the marginal cost of the $x$-good. Since the latter is a necessary social cost, the right hand side does in fact express the net social income generated by work effort at the margin. Thus the condition is equivalent to the first best efficiency condition $M R S=M R T$, and there is no distortion.

It is of interest to interpret these findings further in terms of marginal tax rates. For this purpose it is helpful to distinguish between a gross and a net tax concept, where the latter is defined net of transfers to the consumers in terms of $x$-good provision. The rationale is that a transfer can be perceived as a negative tax. We write the gross tax function as $T(Y)=Y-B(Y)$ and the tax net of the public provision of the $x$-good as $\tau(Y)=Y-B(Y)-p f(Y / w)=$ $=T(Y)-p f(Y / w)$. The corresponding marginal tax rates are $T^{\prime}(Y)$ and $\tau^{\prime}(Y)$, where $\tau^{\prime}(Y)=T^{\prime}(Y)-(p / w) f^{\prime}(Y / w)$. Employing the usual measure of marginal tax rates in the Mirrlees-Stern-Stiglitz tradition we can define $T^{\prime}(Y)$ as $1-M R S_{B, Y}$. As observed from the optimality condition (2) the marginal gross rate for the highest skill type becomes:

$$
T^{\prime}\left(Y^{3}\right)=\left(p / w^{3}\right) f^{\prime}\left(Y^{3} / w^{3}\right)>0
$$

whereas the net tax rate becomes:

$$
\tau^{\prime}\left(Y^{3}\right)=T^{\prime}\left(Y^{3}\right)-\left(p / w^{3}\right) f^{\prime}\left(Y^{3} / w^{3}\right)=0
$$

That is, the marginal income tax should not be zero but should equal the marginal cost of the $x$ good incurred when agent $i$ earns an additional unit of gross income. The implication is that these persons face the same marginal prices as in a situation with no public provision of $x$. Even if true that the individual obtains the $x$-good "for free" from the public sector, it is still the case that the individual acts as if he were facing the real total, as well as marginal, cost of purchasing the $x$ good. They simply pay for it via their tax bill. Hence, the optimal tax/public provision scheme faces the high-skilled individual, locally at the individual's optimum point, with exactly the same budget constraint as in the system where the $x$-good is bought in the market.

One may then ask what difference it makes whether the $x$-good is publicly or privately funded. The answer is that is makes a crucial difference with respect to mimicking. If a person of 
type three (or two) were to mimic, his tax payment would cover the cost of the $x$-good of the mimicked person, which would exceed his own need. While it is true that the tax pays for the $x$ that actual people need at their optimum income points, it pays for more than the $x$ needed by mimickers, which imposes a cost to mimicking. Note also that an individual of type three is likely to complain and argue that he would prefer a system where one does not pay for the $x$-good via the taxes. He would like a system with lower tax payments and all of the $x$-good purchased in the market. The reason is that in such a system he could mimic, obtaining a tax relief exceeding his cost of the $x$-good as a mimicker. However, if the political majority is adamant to retain the previous redistribution, steps would have to be taken to prevent such behavior, and a Pareto inferior situation would arise as compared to a regime with public provision of $x$. Hence, a public provision system, improving upon the market solution, is likely to have the property that some people would like to change it in the hope of escaping the burden of redistribution.

The consumption-leisure bundle of the lower skill groups must be distorted in order to prevent these agents from being mimicked. The marginal income tax of type 1 is:

$$
T^{\prime}\left(Y^{1}\right)=\rho\left(M R S^{1}-M R S^{21}\right)+\left(p / w^{1}\right) f^{\prime}\left(Y^{1} / w^{1}\right)
$$

and the marginal tax net of the cost of the $x$-good is:

$$
\tau^{\prime}\left(Y^{1}\right)=T^{\prime}\left(Y^{1}\right)-\left(p / w^{1}\right) f^{\prime}\left(Y^{1} / w^{1}\right)=\rho\left(M R S^{1}-M R S^{21}\right)>0
$$

Similarly for type 2,

$$
\begin{gathered}
T^{\prime}\left(Y^{2}\right)=\rho_{3}\left(M R S^{2}-M R S^{32}\right)+\left(p / w^{2}\right) f^{\prime}\left(Y^{2} / w^{2}\right) \\
\tau^{\prime}\left(Y^{2}\right)=T^{\prime}\left(Y^{2}\right)-\left(p / w^{2}\right) f^{\prime}\left(Y^{2} / w^{2}\right)=\rho_{3}\left(M R S^{2}-M R S^{32}\right)>0
\end{gathered}
$$

We note that the marginal gross tax is made up of two terms - one reflecting the social marginal cost of the $x$-good and the other being a distortionary term needed to deter mimicking. The part that reflects the social marginal cost is nondistortionary and serves the same role as a market price as it conveys information about the cost of working an additional hour. This is an important insight. Just taking the marginal tax rates at face value one is easily led to exaggerate the distortionary effect as one may easily overlook that part of the marginal tax is indeed a payment for a true social cost. The second part, which appears on its own in the net marginal tax, 
is distortionary. It follows from the expression for the net tax rate that the labour supply of the low-skilled type is distorted downwards. ${ }^{5}$

The marginal tax after taking account of the transfer in kind, is of the same form as the marginal income tax in the pure income tax system. However, now there is an additional term, $\left(p / w^{1}\right) f^{\prime}\left(Y^{1} / w^{1}\right)$, in the expression for the marginal gross income tax. For all actual persons public provision makes the cost of obtaining $x$ no different than if it were purchased in the market. In either case the consumers face both the real total cost and marginal cost of the $x$ good, as is socially desirable since the cost of $x$ is a true cost of supplying labor. The market price and the extra marginal tax, perceived as earmarked for the $x$-good, yield the same labor market disincentives. Only if a person were to mimic, would the public scheme be different than a market system as a mimicker, via the tax system, would be forced to pay for an amount of $x$ equal to that demanded by the person with lower skill, and exceeding the need of the mimicker. This is the crucial property of the public provision system as it is indeed the capability of alleviating the self-selection constraint that is the very justification for the public provision in our context.

\section{Are tax deductions an alternative?}

In some countries the expenses for day care or health care are tax deductible while in other countries there are suggestions that these types of expenditures should be made tax deductible. Is tax deductibility about as good, or maybe better, than public provision? In this subsection we analyze this question. ${ }^{6}$

To study this issue it is sufficient to consider a model with only two skill levels. So to keep down notation we consider a situation with only skill levels $w^{1}$ and $w^{2}$, where as before $w^{1}<w^{2}$. Moreover, to further keep down on notation, we consider the special functional form $f(h)=h=Y / w$, which we think is a good description for the demand for day care ( as discussed in more detail in 5.1 below.) Assume that a fraction $\alpha$ of day care expenses are deductible which means that the tax base is $Y-\alpha p Y / w$. No deductibility and full deductibility obviously correspond to $\alpha=0$ and $\alpha=1$, respectively. Deductibility can be introduced by increasing $\alpha$

\footnotetext{
${ }^{5}$ However, it should be noted that the distortion is less than it would be in a situation with optimal income taxation and where individuals buy the $X$-good in the market.

${ }^{6}$ Efficiency effects of tax deductions for work related expenses have also recently been discussed in Richter (2006) using a different modeling approach than ours. Richter raises doubts about the desirability of some of the deductions that are common.
} 
from zero. Let us assume that the deduction cannot be used to make inferences about working time, e.g. because only the expenditure can be observed such that separate information about hourly fee and number of hours is not available. Mimicking then implies that

$Y^{21}-\alpha p Y^{21} / w^{2}=Y^{1}-\alpha p Y^{1} / w^{1}$

We rewrite this as

$Y^{21}=\theta Y^{1}$.

where $\theta=\left(1-\alpha p / w^{1}\right) /\left(1-\alpha p / w^{2}\right)$. Assuming $p<w^{2}$ we have $0<\theta<1$ and $Y^{21}<Y^{1}$. For future use we note that $d \theta / d \alpha=\left(p / w^{2}-p / w^{1}\right) /\left(1-\alpha p / w^{2}\right)^{2}<0$.

Let us maximise $U^{1}\left(B^{1}-p Y^{1} / w^{1}, Y^{1}\right)$ subject to a given utility for type 2, the selfselection constraint, and the government budget constraint. We formulate the Lagrangian

$\Lambda=U^{1}\left(B^{1}-p Y^{1} / w^{1}, Y^{1}\right)+\lambda_{2}\left[U^{2}\left(B^{2}-p Y^{2} / w^{2}, Y^{2}\right)-\bar{U}^{2}\right]$

$+\beta_{2}\left(U^{2}\left(B^{2}-p Y^{2} / w^{2}, Y^{2}\right)-U^{21}\left(B^{1}-p \theta Y^{1} / w^{2}, \theta Y^{1}\right)\right)+\mu\left(Y^{1}-B^{1}+Y^{2}-B^{2}-R\right)$

We do not write out the first order conditions for this optimization problem but proceed to study the effects of a variation in $\alpha$, i.e. the implication of introducing a right to deduct expenses on the $x$-good where deduction was originally not granted. Using the Envelope Theorem we obtain

$$
\frac{\partial \Lambda}{\partial \alpha}=\beta_{2} Y^{1}\left(U_{B}^{21} \frac{p}{w^{2}}-U_{Y}^{21}\right) \frac{d \theta}{d \alpha}<0
$$

The sign follows from the facts that $U_{B}^{21}>0, U_{Y}^{21}<0$ and $d \theta / d \alpha<0$. This sign of $\partial \Lambda / \partial \alpha$ holds for all values of $0 \leq \alpha \leq 1$. We can conclude that allowing deductibility of day care expenses will result in lower welfare.

To obtain some intuition for the result let us think of a regime where the tax schedule has been optimized with non-deductible day care expenses. Let us then allow deductibility whilst keeping the same income tax schedule in the sense that for a given $Y$ the same tax is paid, i.e. we introduce a tax schedule $S\left(Y-\frac{p}{w} Y\right)$ with the properties that $S\left(Y^{i}-\frac{p}{w^{i}} Y^{i}\right)=T\left(Y^{i}\right)$ for $\mathrm{i}=1,2$.

Then both types are equally well off as before. This is seemingly a "technical" way to redefine the tax schedule. In the original regime type two would mimic by choosing $B^{1}, Y^{1}$. In the new regime he would mimic by choosing $B^{1}, Y^{21} . B^{1}=Y^{1}-S\left(Y^{1}-\frac{p}{w^{1}} Y^{1}\right)=Y^{1}-T\left(Y^{1}\right)$ so the 
mimicker would have the same disposable income as in the original regime. $Y^{21}=\frac{1-p / w^{1}}{1-p / w^{2}} Y^{1}<Y^{1}$ which means that in the regime with deductibility the mimicker would work less while obtaining the same consumption, and mimicking has become a more attractive option.

Hence, we see that tax deductibility is not a substitute for public provision. In fact, as compared to no government intervention in the market for $x$, tax deductibility decreases welfare.

\section{Examples}

The crucial assumption about the publicly provided private good in our model is that conditional on hours of work there is satiation. Given this assumption, a provision system is feasible where all individuals obtain as much as they want of the $x$-good for free. Here we will discuss four examples of services that, to various extents, satisfy this assumption.

\subsection{Day care}

The good that we believe best fits our model is day care. Parents with children in day care ages need someone that takes care of the child when the parents work. Also, since most parents like to spend time with their children and may only want day care in order to be able to work, there would be satiation in hours of day care. We would simply have $x=f(h)=h$. On the margin, if the parents would like to work one hour more, an additional hour of day care is needed and $f^{\prime}$ would equal one. The latter property would also apply if parents would like to demand some fixed day care which is unrelated to working hours, say, in order to have opportunities for shopping., going to the dentist, or doing some unpaid work without being disturbed. Formally, we would then have $x=$ constant $+h=$ constant $+Y / w$, We find that day care fits the assumptions of our model quite well.

It would be of interest to get a rough idea of how large the contribution to the marginal income tax the real cost of day care can be. We use stylized Swedish figures to do a "back of the envelope calculation”. Since there is a clear mode in the distribution of wage rates at the bottom part of the distribution we think this mode can be used as an empirical value for the low-skill wage. Using this mode, a simple back of the envelope calculation indicates that for low income individuals, $p / w_{1}$ amounts to something like $30-35 \%$ if we assume one child is in day care. 
Hence, this part of the marginal tax can be interpreted as a payment for day care. Beyond this there is, according to equation (7), an additional term $\rho\left(M R S^{1}-M R S^{21}\right)$ reflecting the distortion that is needed to deter mimicking. If there are more children in the household the marginal cost of working longer hours is larger as there are more children to pay for in day care. This means that an even larger share of the marginal tax rate reflects a cost of day care rather than a distortion, indicating that our "back of the envelope figure” above is on the lower side

Public provision of day care has strong implications for the design of the optimal income tax schedule that should face individuals with children in day care. This of course also implies that families with children should face other income tax schedules than families without children. Akerlof (1978) argued that the income tax should be differentiated between groups with different observable characteristics. Our analysis provides a further argument for the usefulness of having different tax schedules for different groups of people. ${ }^{7}$

It can also be of interest to see the quantitative importance in terms of how many children who are in some form of day care. As the labor force participation of females has increased in many countries so has the number of children in day care. For example, in Sweden $85 \%$ of children in ages $2-5$ are in day care. ${ }^{8}$ To a substantial part (80-85\%) this child care is publicly financed. In US day care is also common. According to Blau and Currie (2003): "For good or ill, the majority of children in the U.S. and many other high-income nations are now cared for many hours per week by adults other than their parents and school teachers”. Hence, day care is already of great importance in many countries. It also seems that over time it becomes important in more and more countries.

\subsection{Elderly care}

We believe elderly care has strong similarities to day care. In many countries an elderly person is cared for by a near relative like a daughter/son or a (younger) spouse. In Sweden in the past, before the system of publicly provided elderly care was as common as it is now, this was quite usual. Anecdotal evidence suggests that it has been and still is fairly common in the US. In Germany children must by law contribute to the care of their parents.

\footnotetext{
${ }^{7}$ With households supporting different numbers of children one might in general have different tax schedules contingent on the number of children, but we shall not pursue the more general issue of household taxation (see e.g. Cremer et al. (2003) and Schroyen (2003 )).

${ }^{8}$ Calculated from tables 62 and 500 in Statistisk Årsbok 2003.
} 
If a relative is responsible for the care of an elderly person the relative can do the care himself, buy care in the market, or rely on publicly provided care. In the absence of public provision the demand for elderly care for a near relative ought to increase as the potential carer works more. A linear function like for day care is probably not the right function. However, in many cases it seems reasonable that the marginal demand $f^{\prime}$ is close to one for higher levels of labour supply.

There also seems to be satiation. You do not want the carer to visit your elderly relative in need of care more than needed. If visits twice a day are sufficient, you do not want six visits a day.

In Sweden, as an example, the provision system is such that you have to accept the quality of the publicly provided elderly care. ${ }^{9}$ With respect to quantity individuals get according to their needs. In case an elderly person is in need of many visits a day from the care giver he gets it. If the need is large the person is cared for in a nursing home. Hence, elderly care and the way it is provided in Sweden fits our model assumptions quite well.

Elderly care is already of large quantitative importance and, because of the coming demographic changes, will become even more important.

\subsection{Primary education}

Children in ages for primary education can get their education either as home schooling, education in a private school or in a public sector school. In the absence of publicly provided primary education parents would have to undertake home schooling or buy private education. In some countries like US and UK parents have a legal right to educate their children at home and this is a right that is used by some parents. ${ }^{10}$ Like for day care the demand for schooling for children would be an increasing function of the parents' hours of work as parents would have less time for teaching their children when they work more. Also, most parents would still like that their children had time for activities such as playing, rest, and social activities besides being educated. Thus there would be satiation in the demand for hours of primary education.

\footnotetext{
${ }^{9}$ Sometimes the production is private, but the care is paid for with public money.

${ }^{10}$ For US it is estimated that something like $2-4 \%$ of children in relevant ages are educated in home schooling and that the percentage is on the rise. For more information see http://nces.ed.gov/pubs2001/Homeschool/background.asp and http://www.reason.com/news/show/36591.html.
} 
Primary education has the necessary properties to make it suitable for the type of public provision studied in this paper, which means that one might conceivably use public provision of primary education as a screening device to mitigate the informational deficiencies in the tax system. However, in practice education policy is governed by other concerns. In most countries the provision system is not designed so that parents can choose how many hours per week they want to use the public school. Rather, there is a requirement that the children should go to either a private or a public sector school for a certain number of hours per week.

\subsection{Health care}

Even if many or most health problems are not related to work, there can be little doubt that several health problems due to diseases and accidents are related to occupation and the number of working hours. The work-related expected need of health care is likely to increase roughly in proportion to the hours of work, and the demand for this part of health care would thus be workinduced. It is also fair to say that there is satiation in the sense that (most) individuals only want to be treated for their actual health problems. If a person has hurt his right knee, he wants that injury to be cured. He does not want his unhurt left knee or his eye to be operated, even if he would get it for free.

The intention of public health care is to furnish people with care and treatment according to need. This is obviously not a sharply defined concept. The waiting time for treatment may vary and one may choose quality levels with different probabilities of successful cure or prospects for speedy recovery. In practice it is the doctors that define what is adequate treatment, and satiation may be defined by the standards that are actually set.

Health care amounts to around 9\% of GDP in Sweden and 15\% in US. So health care is quantitatively of large importance. Even if only a fraction, but presumably a significant fraction, is work-related we have a quantitatively important good that fits the assumptions of our model fairly well.

\section{Conclusions and discussion}

It is well known since long that public provision of certain private goods can mitigate the selfselection constraint. The important and new insight from the analysis of this paper is that there can be provision systems where individuals get as much as they want/need. For such systems it is 
essential that the true marginal social cost of providing the good is mirrored in marginal income taxes. That part of the marginal tax that reflects the marginal social cost does not have any deadweight loss and plays the same role as a market price in the sense that it conveys information on resource costs.

In some countries public provision of the type of services listed above amounts to something like $15 \%$ of GDP. A substantial part of the marginal taxes individuals face in such countries might therefore be non-distortionary. However, to determine how large part of the marginal tax that is non-distortionary would require careful empirical work and also further theoretical work. Almost all models of public provision of private goods have studied models where all individuals have the same preferences for the publicly provided private good. In real life the need for day care, elderly care etc. varies between individuals. It would be of interest to study how taxes should be set in a model where some individuals have children in day care ages, some have elderly relatives that need care etc. Since it is easy to observe who have children in day care ages, there can be a separate tax schedule for those who have children in day care ages. However, it is harder to observe who feel obliged to take care of an elderly close relative. How should the tax schedule be designed for a group of people where only some have a need for the publicly provided good and it is hard to observe who those are?

An issue addressed in previous work is whether a good partially provided by the public sector should be taxed/subsidised. ${ }^{11}$ We note that in our present model there is no separate role for a commodity tax (subsidy). As the $x$-good is a prerequisite for working, the only thing that matters for work incentives is the net wage obtained after tax and after paying for the $x$-good. However, with respect to the mimicking problem it makes a crucial difference whether there is a fee for the $x$-good, or it is paid for via the tax bill. If there is a fee, a mimicker will escape part of the fee, as compared to the low-skilled person, simply by demanding less of the $x$-good. There is no similar escape from taxes as they are determined by income rather than working hours, and by definition the mimicker and the mimicked person earn the same income. Hence we can conclude that the $x$-good should be fully tax financed, but people should still face the true marginal cost of labour market participation as reflected in the marginal income tax.

Another instrument that might be considered as a substitute to public provision is to make the expenses on $x$-goods tax deductible. However, our analysis shows the opposite. One should

\footnotetext{
${ }^{11}$ See Blomquist and Christiansen (1998) and Boadway et. al (1998).
} 
never make expenses on $x$-type goods tax deductible. Instead of deterring mimicking tax deductibility enhances the possibilities for mimicking.

Let us end by emphasizing some of the most important conclusions. Going from a situation where individuals buy the service in question in the market to a situation where the good is publicly provided, total and marginal taxes will increase. However, part of the marginal taxes will be nondistortionary and total distorsions will decrease while labor supply and welfare increase. An implication of this is that if one compares the tax systems in two countries it may very well be that the country with higher marginal tax rates have less severe distortions than the country with lower marginal tax rates. One cannot judge the distortions generated by a tax system in isolation, one must also consider the expenditure side.

\section{Appendix}

From the Lagrange function (1) we can derive standard first order conditions,

$\Lambda_{B^{1}}=U_{C}^{1}+\beta_{2} U_{C}^{21}-\mu=0$,

$\Lambda_{Y^{1}}=U_{Y}^{1}+\beta_{2} U_{Y}^{21}+\mu\left[1-\frac{p}{w^{1}} f^{\prime}\left(\frac{Y^{1}}{w^{1}}\right)\right]=0$,

$\Lambda_{B^{2}}=\left(\lambda_{2}+\beta_{2}\right) U_{C}^{2}-\beta_{3} U_{C}^{32}-\mu=0$,

$\Lambda_{Y^{2}}=\left(\lambda_{2}+\beta_{2}\right) U_{Y}^{2}-\beta_{3} U_{Y}^{32}+\mu\left[1-\frac{p}{w^{2}} f^{\prime}\left(\frac{Y^{2}}{w^{2}}\right)\right]=0$,

$\Lambda_{B^{3}}=\left(\lambda_{3}+\beta_{3}\right) U_{C}^{3}-\mu=0$,

$\Lambda_{Y^{3}}=\left(\lambda_{3}+\beta_{3}\right) U_{Y}^{3}+\mu\left[1-\frac{p}{w^{3}} f^{\prime}\left(\frac{Y^{3}}{w^{3}}\right)\right]=0$.

The first order conditions can be manipulated to obtain further economic insights. Solving (a1) and (a2) for $-U_{Y}^{1}$ and $U_{C}^{1}$, and dividing, we obtain

$$
\frac{-U_{Y}^{1}}{U_{C}^{1}}=\frac{-\beta_{2} U_{Y}^{21}+\mu\left[1-\frac{p}{w^{1}} f^{\prime}\left(\frac{Y^{1}}{w^{1}}\right)\right]}{\beta_{2} U_{C}^{21}+\mu},
$$

which can be reformulated as 
$\frac{-U_{Y}^{1}}{U_{C}^{1}}\left(\beta_{2} U_{C}^{21}+\mu\right)=-\beta_{2} U_{Y}^{21}+\mu\left[1-\frac{p}{w^{1}} f^{\prime}\left(\frac{Y^{1}}{w^{1}}\right)\right]$.

Straightforward manipulations yield the expression

$\frac{-U_{Y}^{1}}{U_{C}^{1}}\left(1+\frac{\mu}{\beta_{2} U_{C}^{21}}\right)=-\frac{\beta_{2} U_{Y}^{21}}{\beta_{2} U_{C}^{21}}+\frac{\mu\left[1-\frac{p}{w^{1}} f^{\prime}\left(\frac{Y^{1}}{w^{1}}\right)\right]}{\beta_{2} U_{C}^{21}}$

or equivalently

$\frac{-U_{Y}^{1}}{U_{C}^{1}}\left(\frac{\mu}{\beta_{2} U_{C}^{21}}\right)=\frac{-U_{Y}^{21}}{U_{C}^{21}}-\frac{-U_{Y}^{1}}{U_{C}^{1}}+\frac{\mu\left[1-\frac{p}{w^{1}} f^{\prime}\left(\frac{Y^{1}}{w^{1}}\right)\right]}{\beta_{2} U_{C}^{21}}$

Multiplying on both sides, we get

$\frac{-U_{Y}^{1}}{U_{C}^{1}}=\frac{\beta_{2} U_{C}^{21}}{\mu}\left(\frac{-U_{Y}^{21}}{U_{C}^{21}}-\frac{-U_{Y}^{1}}{U_{C}^{1}}\right)+1-\frac{p}{w^{1}} f^{\prime}\left(\frac{Y^{1}}{w^{1}}\right)$.

Then making use of (a3) and (a4) and performing manipulations analogous to those above, we obtain

$\frac{-U_{Y}^{2}}{U_{C}^{2}}=\frac{\beta_{3} U_{C}^{32}}{\mu}\left(\frac{-U_{Y}^{32}}{U_{C}^{32}}-\frac{-U_{Y}^{2}}{U_{C}^{2}}\right)+1-\frac{p}{w^{2}} f^{\prime}\left(\frac{Y^{2}}{w^{2}}\right)$,

(a5) and (a6) readily imply that

$\frac{-U_{Y}^{3}}{U_{C}^{3}}=1-\frac{p}{w^{3}} f^{\prime}\left(\frac{Y^{3}}{w^{3}}\right)$.

\section{References}

Akerlof, G. A. (1978). "The Economics of “Tagging” as Applied to the Optimal Income Tax, Welfare Programs, and Manpower Planning.” American Economic Review 68, 8-19.

AKU 2000, Grundtabeller årsmedeltal 2000. Statistiska Centralbyrån.

Balestrino A. (2000), "Mixed Tax Systems and the Public Provision of Private Goods”, International Tax and Public Finance 7, 463-478

Blau, D. and J. Currie (2003) “Preschool, Day Care and After School Care: Who’s Minding the Kids?”, forthcoming in Handbook of the Economics of Education 
Blomquist, S. and V. Christiansen (1995). "Public Provision of Private Goods as a Redistributive Device in an Optimum Income Tax Model.” Scandinavian Journal of Economics 97, 547567.

Blomquist, S. and V. Christiansen (1998). "Price Subsidies Versus Public Provision”. International Tax and Public Finance 5, 283-306.

Boadway, R. and M. Marchand (1995). “The Use of Public Expenditures for Redistributive Purposes”.” Oxford Economic Papers 47, 45-59.

Boadway, R., M. Marchand and M. Sato (1998). "Subsidies Versus Public Provision of Private Goods as Instruments for Redistribution”, Scandinavian Journal of Economics 100, 545-64.

Cremer, H. and F. Gahvari (1997). “In-kind Transfers, Self-selection and Optimal Tax Policy.” European Economic Review 41, 97-114.

Cremer, H., A. Dellis and P. Pestieau, (2003). "Family Size and Optimal Income Taxation.” Journal of Population Economics 16, 37-54.

Mirrlees, J.A. (1971). “An Exploration in the Theory of Optimum Income Taxation.” Review of Economic Studies 38, 175-208.

Pirttilä, J. and M. Tuomala (2002), "Publicly provided private goods and redistribution: A general equilibrium analysis”, Scandinavian Journal of Economics 104, 173-188.

Richter W. F. (2006), “Efficiency Effects of Tax Deductions for Work-related Expenses.” International Tax and Public Finance 13, 685-699.

Schroyen, F. (2003), "Redistributive taxation and the Household: The Case of Individual Filings”. Journal of Public Economics 87, 2527-2547

Statistisk Årsbok 2003. Statistiska Centralbyrån, Stockholm.

Stern, N.H. (1982). “Optimum Income Taxation with Errors in Administration.” Journal of Public Economics 17, 181-211.

Stiglitz, J.E. (1982). "Self-Selection and Pareto Efficient Taxation.” Journal of Public Economics 17, 213-240. 
WORKING PAPERS*

Editor: Nils Gottfries

2006:7 Mikael Carlsson, Stefan Eriksson and Nils Gottfries: Testing Theories of Job Creation: Does Supply Create Its Own Demand? 23pp.

2006:8 Annika Alexius and Erik Post, Cointegration and the stabilizing role of exchange rates. 33pp.

2006:9 David Kjellberg, Measuring Expectations. 46pp.

2006:10 Nikolay Angelov, Modellig firm mergers as a roommate problem. 21pp.

2006:11 Nikolay Angelov, Structural breaks in iron-ore prices: The impact of the 1973 oil crisis. 41pp.

2006:12 Per Engström and Bertil Holmlund, Tax Evasion and Self-Employment in a High-Tax Country: Evidence from Sweden. 16pp.

2006:13 Matias Eklöf and Daniel Hallberg, Estimating retirement behavior with special early retirement offers. 38pp.

2006:14 Daniel Hallberg, Cross-national differences in income poverty among Europe's 50+. 24pp.

2006:15 Magnus Gustavsson and Pär Österholm, Does Unemployment Hysteresis Equal Employment Hysteresis? 27pp.

2006:16 Jie Chen, Housing Wealth and Aggregate Consumption in Sweden. 52pp.

2006:17 Bertil Holmlund, Quian Liu and Oskar Nordström Skans, Mind the Gap? Estimating the Effects of Postponing Higher Education. 33pp.

2006:18 Oskar Nordström Skans, Per-Anders Edin and Bertil Holmlund, Wage Dispersion Between and Within Plants: Sweden 1985-2000. 57pp.

2006:19 Tobias Lindhe and Jan Södersten, The Equity Trap, the Cost of Capital and the Firm's Growth Path. 20pp.

2006:20 Annika Alexius and Peter Welz, Can a time-varying equilibrium real interest rate explain the excess sensitivity puzzle? 27pp.

2006:21 Erik Post, Foreign exchange market interventions as monetary policy. 34pp.

2006:22 Karin Edmark and Hanna Ågren, Identifying Strategic Interactions in Swedish Local Income Tax Policies. 36pp.

2006:23 Martin Ågren, Does Oil Price Uncertainty Transmit to Stock Markets? 29pp.

\footnotetext{
* A list of papers in this series from earlier years will be sent on request by the department.
} 
2006:24 Martin Ågren, Prospect Theory and Higher Moments. 31pp.

2006:25 Matz Dahlberg, Eva Mörk, Jørn Rattsø and Hanna Ågren, Using a discontinuous grant rule to idenitfy the effect of grants on local taxes and spending. 26pp.

2006:26 Jukka Pirttiläa and Håkan Selin, How Successful is the Dual Income Tax? Evidence from the Finnish Tax Reform of 1993. 40pp.

2006:27 Henrik Jordahl and Che-Yuan Liang, Merged Municipalities, Higher Debt: On Free-riding and the Common Pool Problem in Politics. 34pp.

2006:28 Per Engström, Ann-Sofie Kolm and Che-Yuan Liang, Maternal Addiction to Parental Leave. 18pp.

2006:29 Jonas Björnerstedt and Andreas Westermark, Delay in Bargaining with Externalities. 27pp.

2006:30 Pär Österholm, Incorporating Judgement in Fan Charts. 36pp.

2006:31 Mikael Carlsson and Andreas Westermark, Monetary Policy and Staggered Wage Bargaining when Prices are Sticky. 26pp.

2007:1 Mikael Elinder, Local Economies and General Elections. 26pp.

2007:2 Ouarda Merrouche, The Long Term Impact of French Settlement on Education in Algeria. 19pp.

2007:3 Ouarda Merrouche, The Long Term Effect of Education Spending Decentralization on Human Capital in Spain. 15pp.

2007:4 Erik Post, Macroeconomic imbalances and exchange rate regime shifts. 38pp.

2007:5 Christian Andersson, Teacher density and student achievement in Swedish compulsory schools. 31pp.

2007:6 Thomas Aronsson, Sören Blomquist and Luca Micheletto, Where Should the Elderly Live and Who Should Pay for their Care? A Study in Demographics and Geographical Economics. 22pp.

2007:7 Sören Blomquist and Vidar Christiansen, Public Provision of Private Goods and Nondistortionary Marginal Tax Rates. 17pp.

See also working papers published by the Office of Labour Market Policy Evaluation http://www.ifau.se/ 